\title{
Trace Eyeblink Conditioning in Rabbits Demonstrates Heterogeneity of Learning Ability Both Between and Within Age Groups
}

\author{
LUCIEN T. THOMPSON,${ }^{1}$ JAMES R. MOYER, JR. ${ }^{2}$ AND JOHN F. DISTERHOFT \\ Department of Cell and Molecular Biology, and the Institute for Neurosciences, Northwestern University Medical \\ School, 303 E. Chicago Ave., Chicago, IL 60611
}

Received 12 January 1995; Revised 6 June 1995; Accepted 29 September 1995

\begin{abstract}
THOMPSON, L. T., J. R. MOYER AND J. F. DISTERHOFT. Trace eyeblink conditioning in rabbits demonstrates heterogeneity of learning ability both between and within age groups. NEUROBIOL AGING 17(4) 619-629, 1996.-Rabbits 2 to 41 months of age were conditioned in the $500 \mathrm{~ms}$ trace eyeblink paradigm to cross-sectionally define the age of onset and the severity of age-associated impairments in acquisition of this relatively difficult hippocampally dependent task. Using a strict behavioral criterion of $80 \%$ conditioned responses (CRs), age-associated learning impairments were significant by 24 months of age. Among rabbits that successfully reached this criterion, impairments in acquisition plateaued at 30 months of age. However, the proportion of severely impaired rabbits (that failed to reach the $80 \%$ criterion) continued to increase age dependently. Using an easier criterion of 8 out of $10 \mathrm{CRs}$, behavioral impairments were not detected until 30 months of age, and cases of severe impairment (failure to reach criterion) were rare. Additional controls demonstrated that the deficits observed were not attributable to nonassociative changes that might have artifactually skewed the data. Even severely impaired 36-month-old rabbits were able to reach a criterion of $80 \%$ CRs when switched from a trace to a delay conditioning task that is not hippocampally dependent. The results are discussed in terms of operationally defining and predicting behavioral effects of aging, hypothetical neural mechanisms, and efficient experimental design.
\end{abstract}

Aging Associative trace eyeblink conditioning Behavioral heterogeneity Learning criteria Age of onset Severity

EYEBLINK conditioning has been used as a model system to study interactions between biological aging of the nervous system and age-associated learning impairments (52). Most animal studies of age-associated learning deficits using the eyeblink response have employed delay conditioning paradigms $(5,31,40)$, although it has been reported that trace conditioning is more sensitive to aging (17), at least in the rabbit model system. It should be noted that acquisition of the trace conditioned eyeblink response is blocked by lesions of the hippocampus $(21,26,44)$, while acquisition in the delay paradigm is not affected $(1,38)$. The cerebellum and associated pontine nuclei have been demonstrated to contain the circuitry necessary for elaboration of the conditioned eyeblink response $(51,52)$, including that necessary for performance of previously acquired trace conditioned eyeblinks (58). It has been suggested that the hippocampus and associated cortical and subcortical regions are required in the rabbit for formation of associations between stimuli separated in time $(30,39,42)$. The hippocampus also has a functional role in memory consolidation $(22,62)$, including consolidation of the rabbit conditioned eyeblink response (21, 29,50). Hippocampal function is notably disrupted even in normal aging $(3,14,24,27,28,35)$, and more selectively and preferentially in clinically relevant age-associated disease states such as Alzhei- mer's dementia $(19,53)$. Consequently, we have restricted our investigations of age-associated learning impairments to the $500 \mathrm{~ms}$ trace conditioning paradigm, which requires an intact hippocampus for successful acquisition, with a long-term goal of identifying critical neural mechanisms in the hippocampus and other brain regions contributing to these deficits.

Attention has been called to the fact that insufficient resources are currently available for studying brain aging $(33,37)$, although the incidence of a variety of age-associated behavioral impairments in humans has climbed steadily as modern medicine has prolonged the average life-span in advanced countries $(4,9,43,52)$. Two mammalian species have had widest use in behavioral and biological studies of aging, the rat $(11-13,25,54)$ and the rabbit $(41,46,52)$, although considerable work has been carried out with other species as well $(18,20,36)$. The rabbit eyeblink conditioning model has been promoted for its direct behavioral parallels with studies in aging humans $(41,52,55)$. Some questions regarding this model deserve additional attention.

Rabbits may live for up to 8 years or more (10), considerably longer than rats, which are senescent at 24 to 30 months of age $(3,6,12)$. No clear definitions of the proper age to classify rabbits as aging or impaired are found within the literature, with rabbits

\footnotetext{
${ }^{1}$ To whom requests for reprints should be addressed.

${ }^{2}$ Present address: Department of Psychology, Yale University, New Haven, CT 06520.
} 
above 1 year of age usually referred to as aging rather than aged in studies of age-dependent effects (see Table 1 for a comparison of methods used in peer-reviewed aging rabbit eyeblink conditioning studies). Considerable variance in age, in behavioral paradigms used, and in stimulus relationships within these paradigms can be seen, with the result that an operationally useful definition of the age of an impaired rabbit population has not been clearly demonstrated. The severity of the age-dependent deficits reported also vary considerably across studies with rabbits, even from the same laboratories (see Table 1). Complete definitions (including the variance within samples) of the age of subjects within studies have not been the norm, and animals of a fairly wide range of ages have been used, limiting their comparative utility for quantitative purposes. Because maintenance of rabbits to achieve sufficient age to qualify as aging can be expensive, a clear definition of the age of onset and explications of the severity of age-dependent behavioral deficits are of significant practical importance (33). Issues of optimal experimental design (37) and efficient use of relatively scarce aging animals thus prompted the experiments reported here. This cross-sectional study was designed to characterize and quantify impairments in associative learning utilizing a relatively difficult $500 \mathrm{~ms}$ trace eyeblink conditioning task as uniformly applied over the past several years in our laboratory, to reliably define a population that is behaviorally aging impaired on this task. Additionally, as the degree of impairment reported appears to differ depending on the measure used for quantification, two different criteria of behavioral acquisition in common use were compared to determine which better defined age-dependent behavioral impairments in the rabbit eyeblink trace conditioning paradigm.

\section{METHOD}

\section{Subjects}

The subjects used were 174 female New Zealand white (NZW) rabbits, Oryctolagus cuniculus; 18 were used for comparisons of trace and delay paradigms, 140 for assessment of age-dependent effects on trace conditioning, and 16 for pseudoconditioning studies detailed below. The rabbits were bred for experimental use, and obtained from Kuiper Rabbitry (Gary, IN) or from Hazelton Research Products (Denver, PA). The rabbits were individually housed in our central rabbit colony, and maintained in the climatecontrolled environment on a 14 L:10 D schedule. Rabbits had ad lib access to water, with a diet of approximately $170 \mathrm{~g} /$ day of Teklad $^{\text {TM7 }}$ (Harlan Sprague-Dawley), designed by our staff veterinarians to maintain rabbit health in our restricted colony environment. Certified birthdates were obtained for all rabbits used, and complete records were maintained indicating date of arrival, surgical preparation, and daily weight.

Health was noted daily, and any subjects exhibiting chronic respiratory infections, postsurgical infections, gastrointestinal distress, or other conditions that might interfere with conditioning were not used. Similarly, rabbits that failed to thrive (i.e., did not

TABLE 1

SUMMARY OF PEER-REVIEWED PUBLICATIONS OF EYEBLINK CONDITIONING IN AGING RABBITS, WITH THE REPORTED AGES AND NUMBERS OF AGING RABITS (IN THE CASE OF PHARMACOLOGICAL STUDIES, ONLY VEHICLE OR UNTREATED CONTROLS ARE INCLUDED), THE BEHAVIORAL TRAINING PARADIGMS USED, THE STIMULUS TIMING RELATIONSHIPS, THE BEHAVIORAL CRITERA, AND THE ESTIMATED AGE-RELATED BEHAVIORAL DEFICIT IN ACQUISITION OF THE CONDITIONED EYEBLINK RESPONSE

\begin{tabular}{|c|c|c|c|c|c|c|c|c|c|}
\hline $\begin{array}{l}\text { Study } \\
\text { (Authors) }\end{array}$ & $\begin{array}{l}\text { Mean Age } \\
\text { (months) }\end{array}$ & $\begin{array}{l}\text { Age Range } \\
\text { (months) }\end{array}$ & $n$ & $\begin{array}{l}\text { Training } \\
\text { Paradigm } \\
\text { Used }\end{array}$ & $\begin{array}{l}\text { CS Duration } \\
(\mathrm{ms})\end{array}$ & $\begin{array}{l}\text { US Duration } \\
(\mathrm{ms})\end{array}$ & $\begin{array}{c}\text { CS-US } \\
\text { Interval (Onset } \\
\text { to Onset, ms) }\end{array}$ & $\begin{array}{c}\text { Criterion } \\
\text { (CRs/Trials) }\end{array}$ & $\begin{array}{c}\% \text { Deficit } \\
\text { (Compared to } \\
\text { Young Controls) }\end{array}$ \\
\hline Coffin and Woodruff-Pak (5) & 36 & - & 6 & delay & 500 & 100 & 400 & $\begin{array}{l}3 / 3 \\
5 / 5 \\
8 / 9\end{array}$ & $\begin{array}{l}43 \% \\
48 \% \\
45 \%\end{array}$ \\
\hline Deyo et al. (7) & 37.7 & $32-48$ & 6 & trace & 100 & 150 & 600 & $8 / 10 *$ & $49 \%$ \\
\hline \multirow[t]{2}{*}{ Graves and Solomon (17) } & - & $36-60$ & 8 & delay & 500 & $50 \S$ & 450 & $\begin{array}{l}4 / 5 \\
8 / 10\end{array}$ & $\begin{array}{c}-8 \% * * \\
7 \%\end{array}$ \\
\hline & - & $36-60$ & 7 & trace & 450 & $50 \S$ & 950 & $\begin{array}{l}4 / 5 \\
8 / 10\end{array}$ & $\begin{array}{l}39 \% \\
52 \%\end{array}$ \\
\hline Kowalska and Disterhoft (23) & 38 & $36-42$ & 6 & trace & 100 & 150 & 600 & $64 / 80(80 \%)$ & $* * *$ \\
\hline Powell et al. (31) & 40 & $36-60$ & 4 & delay & 500 & $250 \S$ & $500 \int$ & $10 / 10$ & $38 \%$ \\
\hline Powell et al. (32) & 40 & - & 12 & delay $\approx$ & 1000 & $250 \S$ & $1000 \int$ & $* * * *$ & $45 \% * * * * *$ \\
\hline Solomon et al. (40) & - & $36-50$ & 10 & delay & 500 & 100 & 400 & $* * * *$ & - \\
\hline Solomon et al. (45) & - & $36-42$ & 10 & delay & 500 & 100 & 400 & $* * * *$ & - \\
\hline Woodruff-Pak et al. (56) & $32 \dagger$ & $21-55$ & 8 & delay & 850 & 100 & 750 & $8 / 9$ & $56 \%$ \\
\hline \multirow[t]{2}{*}{ Woodruff-Pak et al. (57) } & 30 & $26-34$ & 5 & trace & 250 & 100 & 750 & $8 / 9$ & $66 \%$ \\
\hline & 45 & $40-50$ & 4 & trace & 250 & 100 & 750 & $8 / 9$ & $72 \%$ \\
\hline Woodruff-Pak and Li (59) & $28.7 \ddagger$ & $21-44$ & 11 & delay & 850 & 100 & 750 & $8 / 9$ & $* * *$ \\
\hline Woodruff-Pak et al. (60) & $29.8 \dagger$ & $24-55$ & 12 & delay & 850 & 100 & 750 & $8 / 9$ & - \\
\hline Woodruff-Pak et al. (61) & 36 & $30-44$ & 6 & delay & $350 \dagger$ & 100 & 250 & $8 / 9$ & $88 \%$ \\
\hline
\end{tabular}

The age of young control subjects ranged from 3 months to 16 months in various studies. All studies used tone CSs and airpuff USs except as noted ( $\$$ shock US; $\uparrow$ mossy fiber stimulation $\mathrm{CS} ; \approx$ a $\mathrm{CS}^{+} / \mathrm{CS}^{-}$differential conditioning paradigm different from all others listed here was used; $\int \mathrm{CS}$ and US did not overlap, instead US onset was coincident with CS offset).

- Cannot be determined from the published report.

* Eyeblink rather than nictitating membrane responses were evaluated. ** A nonsignificant behavioral improvement for aging compared to young control delay conditioned rabbits was reported. *** No comparisons were made to behavior of young rabbits. **** Subjects wre trained a fixed number of trials rather than to criterion. $* * * * *$ Deficit observed primarily for male rather than for female rabbits. $\dagger$ Mean age inferred from published mean for all aging subjects used, although no indication of age-matching within drug treatment groups was published. $\$$ Mean age inferred from published mean for all aging subjects used, although the published report indicated that a significant difference in age between drug treatment groups was found. 
maintain or gain weight prior to or during training) were not used. Neither was a common occurrence (less than $5 \%$ of the rabbits received from suppliers), and no apparent age relationship was noted. Auditory startle reflexes were informally assessed, to ensure that data from rabbits with suspected hearing difficulties were not used. All young and old rabbits used exhibited normal auditory startle responses to novel stimuli. Postmortem examinations indicated that seven rabbits (four under 12 months and three over 24 months of age) omitted from study due to absence of startle responses suffered from inner ear infections, a relatively isolated occurrence observed in considerably fewer than $5 \%$ of the population studied. More formal tests of auditory sensitivity and of other nonassociative effects of aging (33) and of the ability to learn a nonhippocampally dependent eyeblink conditioning task were made for selected subsets of rabbits, and are detailed below. This and more extensive assessment of hearing sensitivity is unfortunately rare in the rabbit learning literature. Although the importance of eliminating sensory- rather than learning-dependent sources of error from learning studies has been stressed $(25,33,37)$, a contrary opinion has been stated that such testing is not necessary due to prior testing in other laboratories (57).

\section{Age Groups}

Young (2-6 months old) rabbits were weaned and virginal. Rabbits 12 months of age were breeding females, but were withdrawn from breeding at least 60 days prior to use. Rabbits 24 months of age or older were retired breeders, and had not been bred or had litters within 60 days of use. Rabbits were divided prior to training into six age groups, 2 months, 4 months, 12 months, 24 months, 30 months, or 36 months of age, which are more fully characterized in Table 2 . The ages given are those of the rabbits on the final day of eyeblink conditioning. Cohort effects were minimized by conducting concurrent experiments within training pairs on rabbits from different age groups. Training was distributed across more than 40 months of time, with no detectable seasonal variation observed in acquisition rates.

\section{Eyeblink Conditioning Experiments}

Behavioral conditioning experiments were controlled by microcomputers using custom hardware and software $(1,47)$. All rabbits were experimentally naive prior to training. Some subjects served as controls in psychopharmacology experiments (8) or were sacrificed at intervals after acquisition and their hippocampal tissue used in receptor binding studies (48) or in biophysical studies of postsynaptic substrates of learning $(29,50)$.

All rabbits were fitted with nylon restraining headbolts, were allowed $48 \mathrm{~h}$ for postsurgical recovery, and then were habituated to restraint in the training environment $(16,26,34)$. Pairs of rabbits were trained in individual sound-attenuated chambers for daily 80 trial sessions, with intertrial intervals averaging $45 \mathrm{~s}$. The right eyelid was held open with stainless steel eyeclips attached to velcro straps, and nictitating membrane (NM, or third eyelid) extension responses were measured noninvasively via changes in light reflectance with an optical detector (47). The tone conditioned stimulus (CS) used was an $85 \mathrm{~dB}, 6 \mathrm{kHz}$ pure tone presented via stereo headphones. The corneal airpuff unconditioned stimulus (US) used in all studies was a $150 \mathrm{~ms}, \sim 3.0$ psi corneal airpuff delivered from a pipette tip placed $3 \mathrm{~mm}$ away from the posterior corner of the right cornea, sufficient to elicit a reliable extension of the NM as the unconditioned response (UR). The same US intensity was used for all subjects, regardless of age, to allow tests for nonassociative differences in somatosensory sensitivity. Only paired CS-US trials were used for trace or delay conditioning studies, to avoid confounds related to CS preexposure or to blocking consequent to unpaired stimulus presentations. A smaller set of rabbits were separately pseudoconditioned, to assess agedependent changes in stimulus sensitivity and motor performance of the eyeblink response. The behavioral comparisons made are described below.

Comparisons of Acquisition in Trace and Delay Conditioning Paradigms. Two groups of six young rabbits each were delay conditioned and one group of six young rabbits was trace conditioned. All were trained to a criterion of $80 \%$ conditioned responses (CRs, defined in all experiments as extensions of the NM beginning after CS onset but prior to US onset) within an 80 trial conditioning session. Specifically, in all experiments, training of rabbits continued using daily 80 trial sessions until the rabbit's performance reached 64 conditioned responses within an 80 trial session (hereafter termed $80 \%$ CRs). Performance was assessed in terms of the number of trials required to reach this rigorous $80 \%$ CRs criterion. Delay conditioning used either a $750 \mathrm{~ms}$ CS (to match the CS-US interval used in trace conditioning) or a $400 \mathrm{~ms}$ CS, used in earlier studies demonstrating no effects of hippocampal lesions on acquisition (1). The CS coterminated with the airpuff US. Defining these delay paradigms by their interstimulus intervals, they are referred to hereafter as Delay 600 and Delay 250 , respectively. For trace conditioning, the $100 \mathrm{~ms}$ duration tone CS was followed (after a 500 ms stimulus-free trace interval) by the airpuff US, which we and others $(7,23,26,44,49)$ have referred to by the duration of the trace interval as Trace 500. All training was carried out in sets of three concurrent pairs to control for cohort effects. Data from these experiments were not included in the age group comparisons shown in Table 2 below, as only young

TABLE 2

BIOLOGICAL AGING DID NOT SIGNIFICANTLY EFFECT EITHER THE UNCONDITIONED RESPONSE OR THE LATENCY OF THE CRs OBSERVED (ASSESSED WITH ANALYSES OF VARIANCE, $p>0.25$ ) IN TRACE 500 EYEBLINK CONDITIONING

\begin{tabular}{|c|c|c|c|c|c|c|c|}
\hline $\begin{array}{l}\text { Age Group } \\
\text { (Nominal) }\end{array}$ & $\begin{array}{c}\text { Mean Age } \\
\text { (months) }\end{array}$ & $\begin{array}{l}\text { Age Range } \\
\text { (months) }\end{array}$ & $\begin{array}{c}n \\
\text { (80\% CRs/Total) }\end{array}$ & $\begin{array}{l}\text { Weight } \\
(\mathrm{kg})\end{array}$ & $\begin{array}{l}\text { UR Amplitude } \\
(\mathrm{mV})\end{array}$ & $\begin{array}{c}\text { UR Peak } \\
\text { Latency (ms) }\end{array}$ & $\begin{array}{c}\text { CR Onset } \\
\text { Latency (ms) }\end{array}$ \\
\hline 2 months & $2.08 \pm 0.04$ & $1.8-2.7$ & $49 / 49$ & $1.4 \pm 0.5$ & $2785 \pm 77$ & $202 \pm 13$ & $315 \pm 10$ \\
\hline 4 months & $3.91 \pm 0.16$ & $3.0-5.2$ & $11 / 11$ & $2.3 \pm 0.2$ & $3011 \pm 155$ & $218 \pm 14$ & $333 \pm 36$ \\
\hline 12 months & $13.71 \pm 0.64$ & $12.2-16.0$ & $7 / 7$ & $2.9 \pm 0.1$ & $3011 \pm 162$ & $174 \pm 23$ & $372 \pm 45$ \\
\hline 24 months & $25.00 \pm 0.44$ & $22.9-27.1$ & $6 / 9$ & $3.4 \pm 0.2$ & $3004 \pm 150$ & $209 \pm 25$ & $371 \pm 34$ \\
\hline 30 months & $30.79 \pm 0.41$ & $28.1-33.0$ & $6 / 14$ & $3.9 \pm 0.1$ & $2966 \pm 140$ & $171 \pm 12$ & $329 \pm 34$ \\
\hline 36 months & $37.46 \pm 0.29$ & $34.2-41.5$ & $20 / 50$ & $4.3 \pm 0.1$ & $2817 \pm 65$ & $200 \pm 9$ & $370 \pm 33$ \\
\hline
\end{tabular}

The number of subjects $(n)$ that reached the $80 \%$ CRs criterion and the number tested per age group are listed. Precise birthdates were obtained for all rabbits from the suppliers. The values listed are means \pm SEM. 
rabbits were used in these experiments, and these data were not included in analyses of age-dependent effects.

Effects of Aging on Trace Eyeblink Conditioning. Rabbits of each age group named above (see Table 2) received Trace 500 eyeblink conditioning as described above (49). A $100 \mathrm{~ms}$ duration tone CS was followed (after a $500 \mathrm{~ms}$ stimulus-free trace interval) by an airpuff US. Training continued using daily 80 trial sessions until the rabbit's performance reached $80 \%$ CRs or for a maximum of 25 training sessions (i.e., up to 2000 paired CS-US trials). Performance was assessed in terms of the number of trials required to reach this rigorous $80 \% \mathrm{CRs}$ criterion. Due to the increased heterogeneity in acquisition observed in aging rabbits, a sufficient number of rabbits in each age group were trained to yield a minimum of six subjects per age group reaching this performance criterion. The number of subjects of each age required to yield samples of this size are shown in Table 2. Performance was also evaluated using other measures, including the number of trials required to reach an easier behavioral criterion, eight conditioned responses in any block of 10 trials ( 8 out of $10 \mathrm{CRs}$ ), and the latency and amplitude of all eyeblink responses.

Auditory Sensitivity in Trace Conditioned Rabbits. Cohort groups of five 4-month and of five 36-month-old rabbits were trace conditioned in the experiments described above until they reached a criterion of $80 \%$ CRs. They were then tested for auditory sensitivity by running three additional sessions using CS intensity gradients, with the CS paired (as during the acquisition phase of the experiment) with the US $(17,33)$. For three sessions on successive days following the session in which they reached the $80 \%$ CRs criterion, rabbits were given blocks of trials in which the auditory CS was presented at intensities of $85,80,75,70$, or $65 \mathrm{~dB}$. The blocks of each CS intensity were pseudorandomized, with three blocks of five successive presentations at each intensity given within a session. Percent conditioned responses at each CS intensity were averaged across the three sessions.

Acquisition of Delay conditioning by Severely Impaired Aging Rabbits. Another crucial test of severely impaired aging rabbits was made to determine if these subjects were able to acquire and perform any conditioned eyeblink response. As noted, delay eyeblink conditioning is not dependent upon the hippocampus for acquisition $(1,38)$ and has been shown to be less severely affected in aging rabbits than is trace conditioning (17). One group of three 36-month-old rabbits was trained in the experiment described above for 25 daily sessions of 80 trace conditioning trials $(2000$ paired CS-US trials total), yet failed to reach criterion. Beginning on the 26th session, the paradigm for training was switched to a delay conditioning paradigm, using a $400 \mathrm{~ms}$ tone CS (of the same intensity and frequency used in trace conditioning) coterminating with the US. Delay conditioning (80 trials per session) was continued over the next several days to determine if the rabbits could reach criterion in this other eyeblink task.

Further Tests of Nonassociative Age-Dependent Changes in the Eyeblink Response. Additional groups of eight 2-month-old and eight 36-month-old rabbits were pseudoconditioned, to control for nonassociative age-dependent changes in performance of eyeblinks in the paradigm used (33). Pseudoconditioned rabbits received explicitly unpaired presentations of the same $100 \mathrm{~ms}$ tone CS and $150 \mathrm{~ms}$ airpuff US used for trace conditioning at intertrial intervals averaging $22.5 \mathrm{~s}$ for 10 daily sessions. Pseudoconditioned rabbits thus received the same number of unpaired stimuli at the same rate as paired stimuli were received by conditioned rabbits within a session. Pseudoconditioned responses were analyzed as controls for nonassociative changes that might confound associative learning by aging subjects. Pseudoconditioning data was averaged across all 10 sessions.

\section{Statistical Analyses}

Behavioral data, except as noted, were tested for main effects of age with analyses of variance (Statview II, Abacus Concepts). Posttests were carried out with Fisher's protected least significance tests. A minimal criterion for statistical significance of $p<0.05$ was used. Behavioral data are cited as means \pm standard error of the means. Mean learning curves for each age group were also constructed, expressed as the percentage of conditioned responses per daily block of 80 training trials. Using linear interpolation algorithms (IgorPro ${ }^{\mathrm{TM}}$, WaveMetrics), each curve was normalized to the mean number of trials required to reach criterion for that group, so that qualitative summaries of learning rates for animals requiring different numbers of trials to reach criterion could be made. For additional statistical comparisons of learning rates between groups, the slopes of individual least squares fitted lines for each subject's nonnormalized learning curve (percent CRs per daily session plotted over sessions) were tested with analyses of variance as previously described (49). Data from rabbits that failed to reach the $80 \%$ CRs criterion were examined separately, were compared separately to data from those that reached criterion, and are discussed separately below.

\section{RESULTS}

\section{Comparisons of Acquisition in Trace and Delay Conditioning Paradigms.}

The Trace 500 eyeblink conditioning task was difficult even for young (4-month-old) rabbits to learn. As seen in Fig. 1, rabbits required more than three times as many trials to reach criterion for acquisition of the conditioned response when the Trace 500 paradigm was used for training as compared to two different delay paradigms, one with a CS-US interval identical to that used for trace conditioning (Delay 600) and one with a quite different CSUS interval (Delay 250). Trace 500 conditioned subjects required significantly more paired CS-US trials $(880 \pm 47)$ to reach a behavioral criterion of $80 \%$ CRs than did delay $600(256 \pm 25)$ or delay $250(272 \pm 44)$ conditioned subjects, $F(2,15)=40.3, p<$ 0.0001 . Posttests indicated no significant difference in trials to reach criterion in comparisons between the two delay paradigms ( $p$ $>0.7$ ). As noted in earlier studies (17), aging rabbits required significantly more training to acquire a trace than a delay conditioned eyeblink response. The more difficult Trace 500 paradigm was used in subsequent studies to define the age of onset of agedependent learning deficits in rabbits, and to examine issues related to definition of this age of onset.

Aging-Impaired Acquisition of Trace Eyeblink Conditioning. Aging significantly impaired acquisition of trace eyeblink conditioning, with the age of onset of impairment differing dependent on the criterion used to measure impairment (see Fig. 2). Rabbits through 12 months of age exhibited similar rates of acquisition, in terms of the number of trials required to reach either behavioral criterion. In rabbits 24 months of age, however, impaired acquisition of Trace 500 eyeblink conditioning was observed, with an increase in the number of trials required to reach different behavioral criteria. Marked age-dependent heterogeneity in learning ability was also observed, with considerable numbers of older rabbits unable to reach a behavioral criterion of $80 \%$ CRs (see the sections on severe impairment below).

Impairment With $80 \%$ CRs Criterion. Comparisons revealed a significant effect of age (see Fig. 2A) on the number of trials required to reach the rigorous $80 \%$ CRs criterion, $F(5,96)=$ $16.27, p<0.0001$. No significant differences in the number of trials required to reach this criterion were found in posttests comparing the acquisition of rabbits 12 months of age or younger $(p>$ 


\section{A 4 mo rabbits}

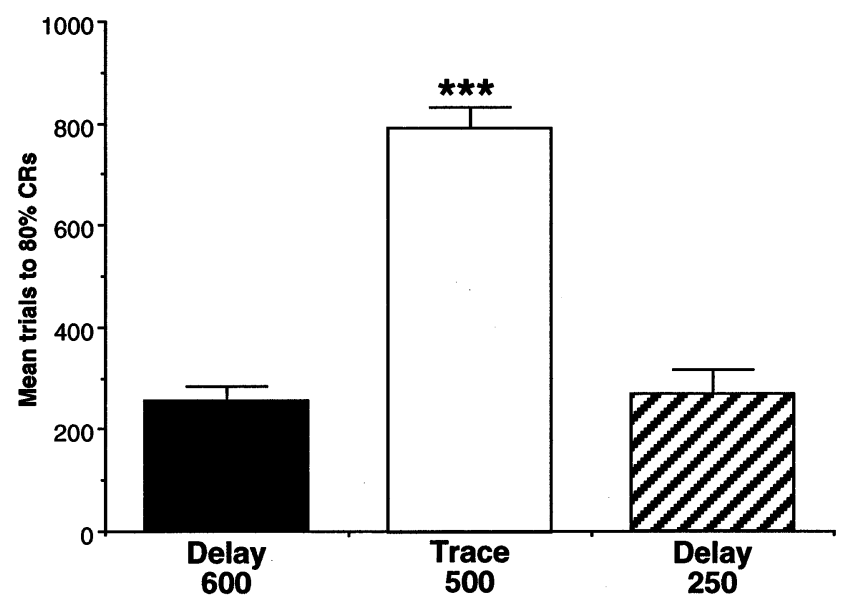

B
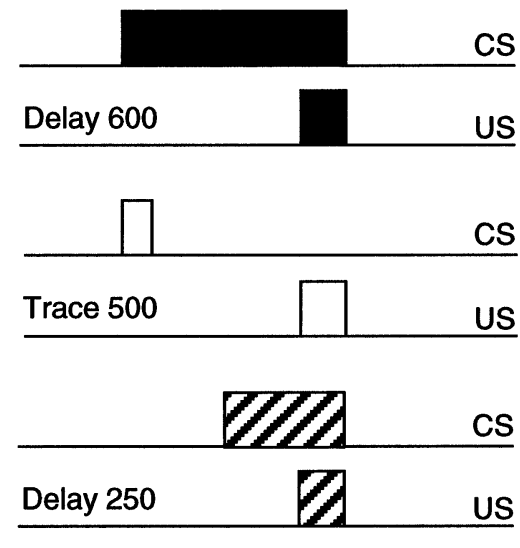

$500 \mathrm{~ms}$

FIG. 1. Acquisition of the conditioned nictitating membrane eyeblink response was significantly slower when young (4-month-old) subjects were trained in a $500 \mathrm{~ms}$ trace paradigm (Trace 500) rather than in delay paradigms with identical CS-US intervals (Delay 600) or quite different CS-US intervals (Delay 250). (A) Trace 500 conditioned rabbits required significantly more training to reach a behavioral criterion of $80 \%$ conditioned responses $(80 \%$ CRs) than did delay conditioned subjects $(* * *<0.0001)$. (B) The delay and trace paradigms that were tested. In the delay paradigms the CS coterminated with the US, while in the trace paradigm an interstimulus trace interval intervened prior to US onset. The airpuff US in all paradigms was identical in intensity and duration; all CSs used the same frequency and amplitude pure tone signal.

0.39). However, posttests indicated that rabbits 24 months of age required significantly more trials to reach criterion than younger rabbits $(p<0.01)$. Rabbits 30 months of age required significantly more trials to reach criterion than did rabbits 12 months of age or younger $(p<0.0006)$. Rabbits 36 months of age required significantly more trials to reach criterion than did rabbits 24 months or age or younger $(p<0.04)$. No significant differences in the number of trials required to reach criterion were found in posttests comparing acquisition of 30-month and 36-month-old rabbits $(p>$ $0.97)$, suggesting that a plateau in age-associated learning impairment may have been reached by 30 months of age. It is unlikely that this plateau is stable, as limited unpublished data from Richard Thompson's laboratory has been reported indicating that rabbits 60 months of age are significantly slower than 36-month-old rabbits at acquiring a delay conditioned eyeblink task [see $(55,57)]$.

Different Impairment with 8 out of 10 CRs Criterion. As seen in Fig. 2B, aging also significantly impaired acquisition as measured with the less rigorous behavioral criterion of 8 out of $10 \mathrm{CRs}$, $F(5,96)=10.74, p<0.0001$. Nearly $99 \%$ of the subjects tested attained the 8 out of 10 CRs criterion (the sole exception was two 36-month-old rabbits, each of which exhibited blocks of 7 out of 10 CRs several times). Posttests of acquisition using the 8 out of 10 CRs criterion indicated that only rabbits 30 months or older were significantly impaired compared to younger rabbits $(p<$ 0.0001 ). No significant differences in trials required to reach the 8 out of 10 criterion were found between 30-month and 36-monthold rabbits $(p>0.32)$, again indicating that age-associated learning impairments in trace conditioning plateaued around 30 months of age.

Correlation analyses indicated that the trials required to reach 8 out of 10 CRs was a moderate predictor of trials to reach the $80 \%$ criterion $\left(r^{2}=0.46, p<0.01\right)$. These modest correlations corroborate the differences between the different behavioral criteria, which yielded different pictures of the age of onset and the severity of age-associated behavioral impairment. The stricter or more dif-
A

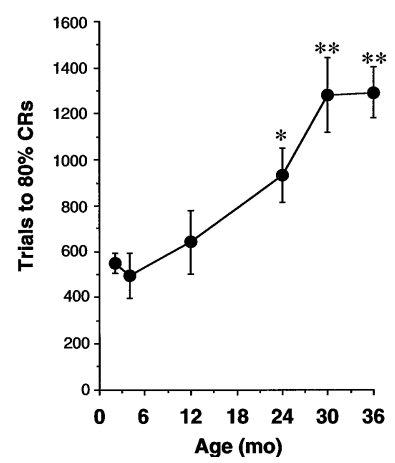

B

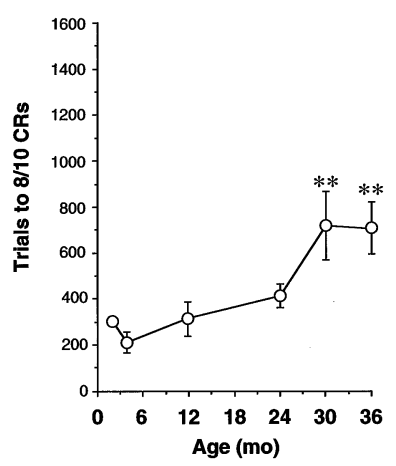

FIG. 2. Aging impaired acquisition of trace eyeblink conditioning differentially, depending upon the behavioral criterion measured. Only data from rabbits that reached the stringent behavioral criterion of $80 \%$ CRs within an 80 trial session are shown. (A) Rabbits 12 months of age or younger reached a criterion of $80 \%$ CRs within a session in approximately equal numbers of trials, with no significant differences between the three young age groups tested (see Table 2). Rabbits 24 months of age or older, however, were significantly impaired compared to younger rabbits. The impairment measured using this strict behavioral criterion plateaued at 30 months of age, with no significantly greater impairment observed in 36month-old rabbits. Twenty-four-month-old rabbits were not as severely impaired as older rabbits. (B) When acquisition was assessed via a simpler behavioral criterion, performance of eight conditioned responses in a block of 10 trials (8/10 CRs), age-associated learning impairments were observed only in rabbits 30 months of age or older. Again, no increase in impairment was seen when comparing acquisition of 36-month-old rabbits to that of 30 -month-old rabbits. Acquisition to this easier behavioral criterion by rabbits 24 months of age or younger was similar across age groups and required significantly less training to attain than for rabbits 30 months or older. 
ficult the criteria, the younger the age-dependent onset was observable.

Age-Dependence of Behavioral Heterogeneity. Behavioral heterogeneity, in terms of the ability or inability to reach a criterion of $80 \%$ CRs, occurred in rabbits of 24 months of age or more, and increased with greater age. Both the number of trials to criterion (reflecting shallower and, therefore, slower learning curves, seen in Fig. 3A) and the proportion of rabbits that failed to learn the task successfully (see Fig. 3B) were found to increase age-dependently. Altered learning rates were observed by testing the slopes of the line least-squares fitted to each subject's learning curve. Comparisons of the slopes of these lines between age groups indicated an age-dependent decrement in learning rates, $F(5,96)=13.41, p<$ 0.0001 . Posttests showed that the slopes of the learning curves for rabbits under 12 months old did not differ significantly from one another $(p>0.11)$. The learning rate (slope) for 24-month-old rabbits that successfully acquired the task was significantly slowed compared to that of 2-month $(p<0.002)$ or 4-month-old $(p<$ 0.0003 ) rabbits, but did not differ significantly from that of older (30- or 36-month) rabbits that also acquired the task $(p>0.38)$. No significant differences in learning rate were found between 30 month and 36-month-old rabbits that reached the $80 \%$ criterion $(p$ $>0.86$ ), although they were significantly slowed compared to 12 month or younger rabbits $(p<0.0001)$.

Increasing Age-dependent failure to Reach $80 \%$ CRs Criterion. Severely impaired aging rabbits failed to perform a significant number of conditioned responses, even after 2000 training trials (see Figs. 3 and $4 \mathrm{~A}-\mathrm{C}$ ). This failure to reach criterion among rabbits 24 mnths of age or older significantly increased with increasing age, $F(2,38)=5.10, p<0.01$. Posttests indicated that more 36-month-old rabbits were severely impaired than 24-month $(p<0.01$; see Fig. 3B). Given sufficient additional training, it is possible that some severely impaired rabbits might have reached the $80 \%$ criterion. Linear extrapolation from the available data, however, indicates that on average, 24 month severely impaired rabbits would require an additional 2320 more training trials (i.e., at least 29 additional daily training sessions). [Note: although Prokasy (34) suggested that acquisition of eyeblink conditioned responses is a multistage process, linear fits offer reasonable first order approximations for describing the learning curves. Indeed, linear fits for learning curves for young subjects had an $r^{2}=0.83$ ].
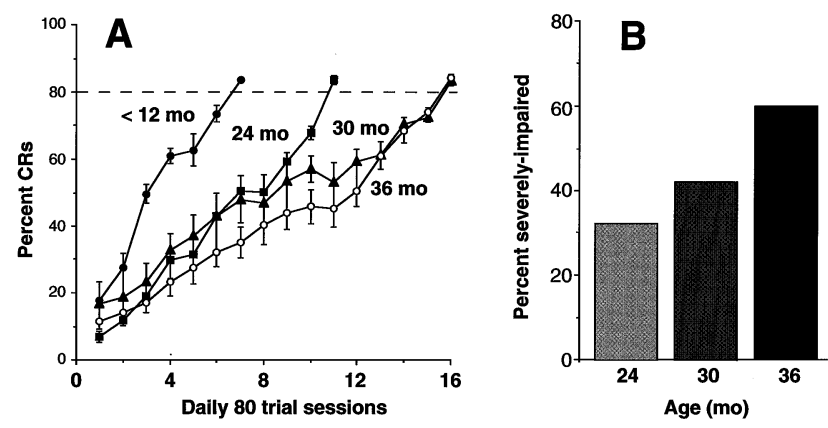

FIG. 3. Age-associated impairment of the acquisition of trace eyeblink conditioning was heterogeneous, with some aging rabbits acquiring the task successfully although more slowly than younger rabbits (i.e. reaching a criterion of $80 \%$ CRs within 2000 training trials or less), while others were unsuccesful in acquiring the task. A. Average learning curves for young rabbits $(<12 \mathrm{mo})$ and for aging rabbits are shown, normalized to the mean trials required for successful acquisition by subjects in each age group. B. The proportion of severely-impaired rabbits failing to reach the $80 \%$ CRs behavioral criterion increased steadily as a function of age beyond 24 mo.
Extrapolations of the slopes of the learning curves for 30-month and 36-month-old severely impaired rabbits indicate that at least 210 daily training sessions $(16,800$ trials) would be required for these rabbits to reach the $80 \%$ criterion. These extrapolations indicate that the impairment of severely impaired rabbits was also age-dependent, as 24-month-old rabbits exhibited less (although still profound) impairment as compared to older rabbits. The heterogeneity observed, with some aging rabbits impaired relative to young rabbits but acquiring the task with more training, and some very severely impaired aging rabbits failing to acquire the task as operationally defined, could not be attributed to any measured changes in sensory responsivity (see below, and Fig. 4D and E).

The observed behavioral heterogeneity (slowing of learning and failure of learning) was not an artifact of measures centered upon the end point of the behavioral training process, as seen in Fig. 5. In an analysis of data from the first 400 training trials (i.e., relatively early in training, particularly for aging subjects), it was observed that the cumulative number of CRs emitted even early in training was age-dependent, with more CRs observed for younger than for older subjects. Further, this trend was heterogeneous, with severely impaired rabbits exhibiting significantly fewer CRs early in training than age-matched cohorts who successfully reached criterion, $F(1,59)=29.879, p<0.0001$. It can be seen that rabbits failing to produce 30 or more CRs early in training without exception failed to reach criterion, even after 2000 training trials.

No Effects of Age on Performance Components of the Eyeblink Response. Aging did not affect nonassociative behavioral measures of the unconditioned NM response during conditioning, including UR amplitude, $F(5,119)=0.92, p>0.45$, or UR peak latency, $F(5,119)=0.77, p>0.5$. The onset latency of CRs emitted by conditioned rabbits was also unaffected by aging, $F(5$, $119)=1.19, p>0.3$. Similarly, aging had no effects on tests of CS-intensity attenuation. Notably, no differences were found during conditioning trials in measures of UR amplitude, $F(1,123)=$ $0.11, p>0.74$, or UR peak latency, $F(1,123)=0.01, p>0.97$, when comparing the performance of successful aging learners (rabbits 24-months of age or older that reached the $80 \%$ criterion) to that of severely impaired aging rabbits (rabbits 24 months of age or older that failed to reach criterion). Table 2 indicates that unconditioned responses were similar in both young and aging rabbits. Data for all trace conditioned subjects are shown by age group.

No Effects of Age on Responses to Unpaired Presentations of the CS or US. Aging had no significant effects on measures of the unconditioned response in pseudoconditioning, including UR amplitude, $F(1,14)=0.71, p>0.3$, or UR peak latency, $F(1,14)=$ $0.82, p>0.6$. The percentage of eyeblink responses emitted by pseudoconditioned rabbits within the $500 \mathrm{~ms}$ following the unpaired CS (the time period defined as the trace interval in paired CS-US training) was also unaffected by aging, $F(1,14)=0.88, p$ $>0.35$. Further, both the UR amplitude, $F(1,139)=0.49, p>0.5$, and peak latency, $F(1,139)=0.32, p>0.72$, of pseudoconditioned rabbits was indistinguishable from that of conditioned rabbits, again indicating that the behavioral preparation was stable across age groups and that the observed age-associated deficits were associative rather than nonassociative in nature.

No Effects of Age on CS Intensity Discrimination. Although sensitivity to the airpuff US was not affected by aging, the possibility that age-dependent learning deficits and/or severe deficits could be due to hearing loss was considered and tested in two ways. First, CS-intensity discrimination in successful learners was examined, to determine if their slowed learning might be attributable to a loss of hearing sensitivity. CS-intensity discrimination was unaffected by aging (see Fig. 6), with 36-month-old rabbits able to discriminate and respond to tones of varying intensities 

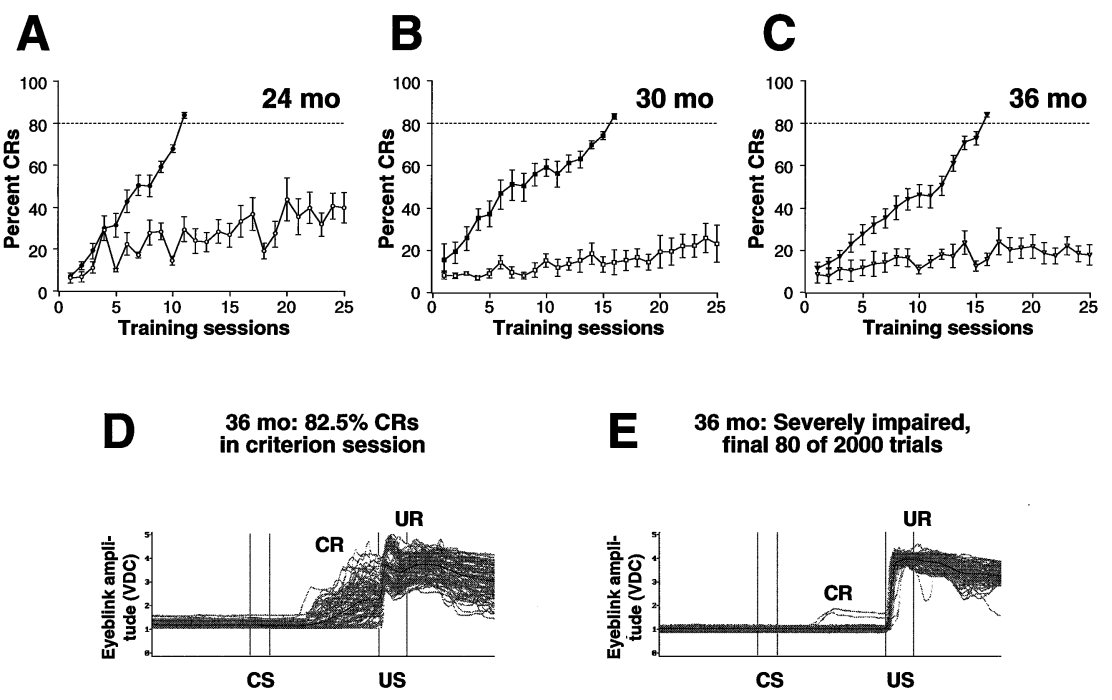

FIG. 4. Quite dissimilar behavior was displayed by aging rabbits that reached criterion and those that did not. (A-C) Learning curves for rabbits that reached criterion in each aging group (closed symbols) and those that failed to reach criterion (open symbols) are shown. As can be seen, the severity of impairment for noncriterion rabbits increased with increasing age, with little or no learning evident for 36-month-old severely impaired rabbits. Evidently the impairment, at least for 30- and 36-month-old rabbits, was not an artifact of insufficient training trials. (D) Trial by trial eyeblink responses (grey traces) and the average conditioned eyeblink response for a training session (black trace) for a 36-month-old rabbit that successfully acquired the task. (E) Equivalent responses from a 36-month-old rabbit in the same cohort, which failed to reach criterion even after 2000 training trials. Note that unconditioned responses were unimpaired in aging, even in cases of severe learning impairment (see Table 2). Severely impaired subjects exhibited a low frequency of responses resembling normal $\mathrm{CRs}$, interspersed widely among trials.

equally as well as young rabbits. Both age groups exhibited a fairly linear decrement in responding to tones up to $15 \mathrm{~dB}$ less intense than the $85 \mathrm{~dB}$ tone to which they were conditioned, and emitted relatively few CRs to $65 \mathrm{~dB}$ tones. Note that even the two most severely impaired 36-month-old rabbits reached performance levels of at least 7 out of 10 CRs. The fact that even severely impaired aging rabbits emitted CRs that exhibited relatively normal response topography and timing (see Fig. 4E), and that even these severely impaired subjects were typically successful at attaining the easier 8 out of $10 \mathrm{CRs}$ criterion (and, thus, would have been classed as successful learners in most other studies of aging), also argues against the deficits being solely attributable to a loss of auditory acuity, even for the relatively brief $100 \mathrm{~ms}$ CS used in these and other aging studies $(4,7,23)$. Thus, the behavioral impairments observed could not readily be attributed to nonassociative changes in auditory sensitivity, at least not for those rabbits that successfully acquired the task.

Even Severely Impaired Rabbits Were Able to Acquire Delay Conditioned Eyeblink Responses. The CS intensity discrimination experiment detailed above does not rule out the possibility that rabbits that failed to acquire the task suffered from hearing deficits that prevented an association being made between the (hypothetically difficult to hear) $85 \mathrm{~dB}$ tone CS and the airpuff US. As seen in Fig. 7, however, even the severe behavioral impairments leading to behavioral heterogeneity may not be attributable to hearing impairments. All three severely impaired rabbits switched from Trace 500 to Delay 250 conditioning after 2000 trace conditioning trials successfully acquired the Delay 250 conditioning task, and required only 320 Delay 250 training trials to reach the criterion of $80 \%$ CRs per session. This argues against a sensory deficit, at least for a moderately short ( $250 \mathrm{~ms}$ duration) tone, and against a deficit in all associative learning abilities in the aging population. Rather, severely impaired rabbits exhibited a specific deficit in their ability to successfully acquire the Trace 500 but not the Delay 250 conditioned eyeblink response.

\section{DISCUSSION}

It has become apparent that biological aging is a product of more than the simple passage of time. Time, however, is clearly a dominant variable in the multiple processes subsumed under the term aging. Aging appears to progress at different rates in different individuals, producing a wide range of changes in neural systems, including those supporting learning and memory. Human subjects have demonstrable age-dependent heterogeneity in their ability to successfully acquire a conditioned eyeblink task (43). Increased variance in acquisition rates in rabbit eyeblink conditioning has also been reported, using a relatively simpler behavioral criterion (57). As the results of the current study also demonstrate (and as numerous other studies with a variety of systems have also shown), animals of the same age can differ significantly from one another across multiple behavioral measures. This between-subject variance also dramatically increases with age. The diversity of behavioral outcomes in learning studies should not be downplayed, and has been noted in studies of human eyeblink conditioning $(33,41$, 55). In the present study, for example, a few individuals in even the youngest age groups exhibited learning rates similar to those of much older individuals. The major shift with aging was in the central tendency of each age group, with increasingly older rabbits on average requiring successively more training to acquire a given task. Additionally, the failure rate (i.e., the proportion of the population unable to successfully acquire the task) exhibited a clear age dependence. 


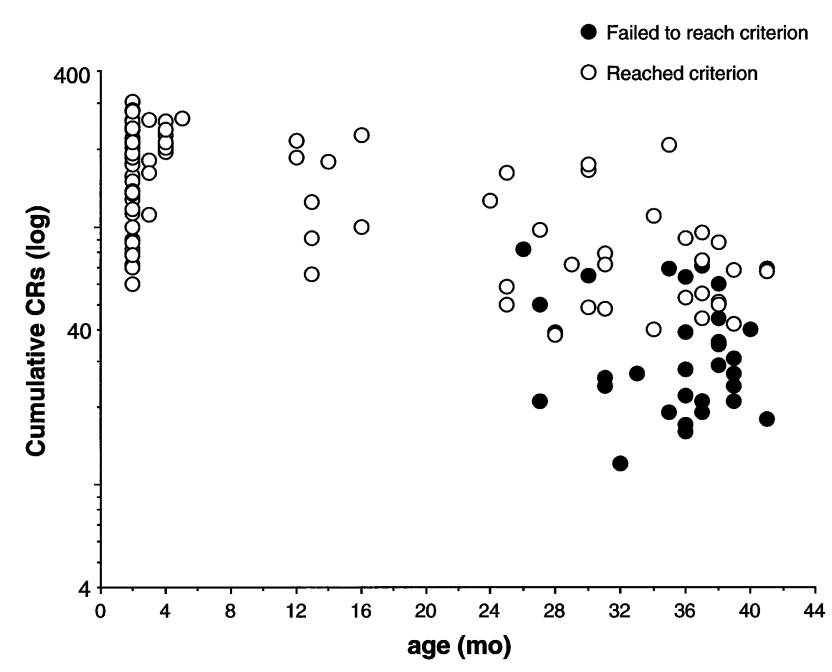

FIG. 5. Learning deficits were observable even relatively early in training (i.e., within the first 400 training trials). Aging rabbits exhibited fewer cumulative CRs within this interval than did younger rabbits. Further, although all ages of rabbits exhibited variability in this measure, the heterogeneity observed among aging rabbits was functionally quite significant. Rabbits failing to exhibit more than 30 CRs within the first 400 trials without exception failed to successfully reach the $80 \%$ CRs criterion, even after 2000 training trials.

A notable finding of the present study was that the behavioral criterion used to measure learning in aging rabbits strongly influenced estimates of both the age of onset of impairment and the very nature of the impairment. Using a simple 8 out of $10 \mathrm{CRs}$ criterion, for example, the data from the current experiments indicated that rabbits are not significantly impaired in trace eyeblink conditioning until they reach approximately 30 months or more of age (see Fig. 2B). Using the more rigorous $80 \%$ CRs criterion, however, significant impairments were observed by approximately 24 months of age (see Fig. 2A). Analyses of the slopes of the learning curves also corroborated this finding. A 6-month difference in the age of rabbits either impaired or not impaired in learning represents a considerable investment at current per diem charges from most rabbitries or institutional animal care facilities (33).

Additionally, the more rigorous $80 \%$ CRs criterion but not the easier 8 out of 10 criterion demonstrated clear age-dependent behavioral heterogeneity (i.e., a division between aging rabbits that were slowed but successful and those that were severely impaired or unsuccessful; see Figs. 3 and 4). Although occasional failure to reach criterion has been reported $(7,61)$, the wide variance in behavioral criteria and, indeed, in behavioral paradigms used in other aging rabbit eyeblink conditioning studies (see Table 1) makes cross-sectional assessment of behavioral heterogeneity in rabbits of different ages very difficult. The effects observed here were not readily attributable to simple nonassociative changes, such as reduced sensitivity to somatosensory stimuli (the corneal airpuff US), and are unlikely to be attributable to reduced acuity in hearing the auditory CS (see cautionary note below). Relatively few studies similar to the present one [e.g., $(5,7,59)$ ] follow Powell's suggestion (33) that nonassociative age-dependent changes be ruled out by the use of pseudoconditioned controls. Measures from conditioning trials, from pseudoconditioning control experiments, from CS-intensity discrimination studies, and from the successful Trace 500 to Delay 250 paradigm switch all indicated that the aging rabbits tested were in many ways comparable to young rabbits, with the exception of a notable decline in the rate of or apparent capacity for successfully acquiring a difficult eyeblink conditioning task.

It should be noted that the Trace 500 eyeblink conditioning task described here utilized a brief $100 \mathrm{~ms}$ duration tone CS. This is shorter than the $250 \mathrm{~ms}$ (57) or $500 \mathrm{~ms}$ (17) duration tone CSs used in some prior studies of trace conditioning in aging rabbits. Considerable debate in the literature has argued that CS duration, CS-US interval, US modality, US intensity, and other factors may contribute significantly to age-dependent learning deficits. However, the lack of consistency in paradigms found in the literature makes comparative analyses difficult. As can be seen in Table 1, seldom is only a single one of these factors different between studies, thus making causative declarations assertive rather than definitive. Comparisons of our own data with that from another study of aging rabbits using a trace conditioned NM task and an airpuff US (57) indicate that acquisition with a $100 \mathrm{~ms}$ duration CS may be somewhat faster than in tasks with longer CS durations. Our 2-month-old rabbits reached a criterion of 8 out of 10 CRs in $309 \pm 28$ trials, while 3 -month-old rabbits in the earlier study (57) reached the same criterion in 349 trials (variance not reported). Our 30-month-old rabbits reached a criterion of 8 out of 10 CRs in $705 \pm 144$ trials, while 30-month-old rabbits in the earlier study (57) reached the same criterion in 1058 trials (variance also not reported). This does not definitively rule out the possibility that severely impaired aging rabbits experienced a unique difficulty in perceiving or processing the brief tone CS in the Trace 500 task, but were somehow able to process a longer tone to acquire the Delay 250 task. But parsimony and the data both tend to argue against such a mechanism.

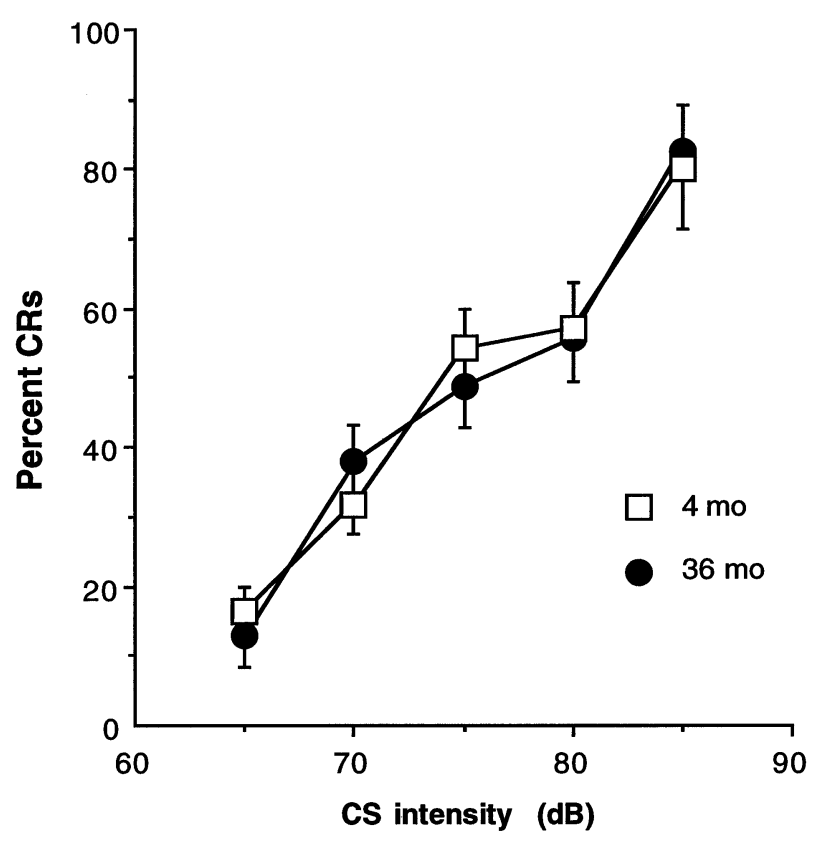

FIG. 6. Auditory sensitivity and paired conditional discrimination was assessed for a group of young (4-month-old) and a group of aging (36month-old) rabbits after successful acquisition. Both groups exhibited high rates of conditioned responses to tone CSs of the same intensity with which they had previously been trained, and discriminated changes in tone intensity equally well, with decreased frequency of responses to less intense tone CSs. The CS intensity discrimination observed for the two age groups thus did not differ significantly. Performance of either age group to paired tone CSs at $65 \mathrm{~dB}$ was indistinguishable from that observed after presentation of unpaired $85 \mathrm{~dB}$ tones in pseudoconditioning. 


\section{"Severely impaired” aging rabbits could learn a non-hippocampally dependent eyeblink task readily}

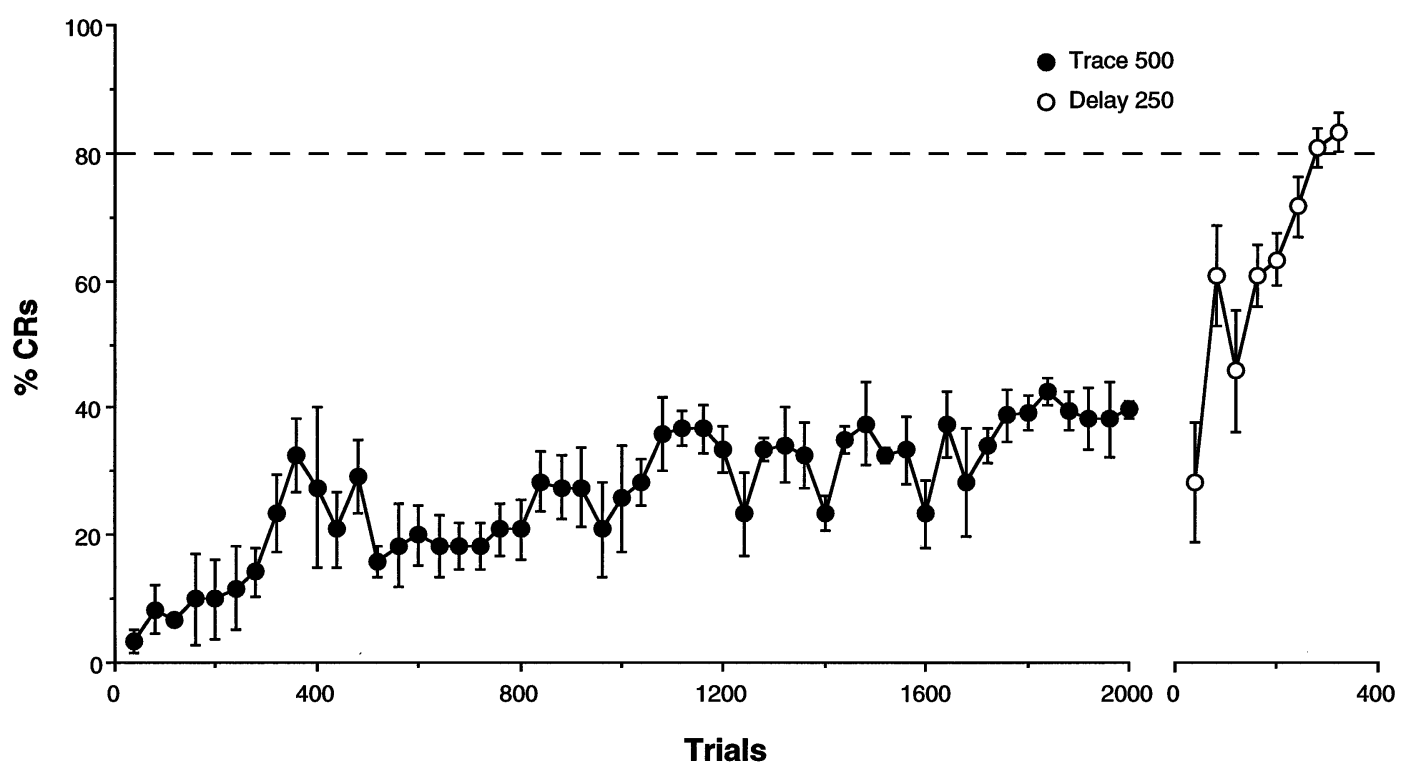

FIG. 7. Aging rabbits that could not successfully acquire the trace eyeblink conditioning task could be successfully delay conditioned. A group of rabbits that failed to reach the $80 \%$ CRs criterion in the Trace 500 task, where the CS and US never overlap in time but are separated by a $500 \mathrm{~ms}$ interstimulus trace interval, were switched after 2000 training trials ( 25 days of 80 trials per daily session) to an easier Delay 250 conditioning task. The same CS and US intensities were used, but in the delay paradigm the CS and US temporally overlapped and coterminated (see Fig. 1B). All severely impaired rabbits switched in this fashion reached $80 \%$ CRs or better after only 320 delay conditioning trials. Thus, aging rabbits apparently did not fail to acquire the Trace 500 conditioning task due to an inability to hear the tone CS, and were unimpaired in their ability to acquire a delay conditioned eyeblink response.

No global learning impairment was noted, but rather a delimited impairment in specific learning and memory tasks. This is reminiscent both of the nonglobal declines in learning and memory seen in aging human populations $(14,33,41,52,55)$ and of the lack of reported age-dependent changes in other tasks, including extinction of the conditioned eyeblink response, seen in aging rabbits (17). The relative ease that even aging rabbits severely impaired on the Trace 500 task had in acquiring the Delay 250 task also argues against a global deterioration in the brain circuitry contributing to acquisition of the conditioned eyeblink response. The trace to delay paradigm shift data suggest that age-dependent hippocampal dysfunction may have strongly contributed to the observed agedependent deficits in acquisition of the Trace 500 task. As noted earlier, the Trace 500 eyeblink task has been demonstrated to require hippocampal function for successful acquisition $(21,26$, 44), while the Delay 250 task does not (1), exhibiting essential dependence on cerebellar circuitry (51). This issue clearly deserves additional investigation, to determine if the degree of individual impairment in learning ability correlates with age-dependent changes in function of the hippocampus as well as of other brain regions.

The degree of behavioral impairment observed for successful learners using either of the behavioral criteria $(80 \%$ or 8 out of 10 CRs) appeared to plateau around 30 months of age, with 36month-old rabbits equally impaired. Whether this plateau persists throughout the remainder of the life-span remains an open question, at least in quantitative terms, but is certainly amenable to further testing. The increase in the proportion of the population that failed to successfully acquire the task across the age range from 30 to 36 months suggests that this would tend to increase with further aging. The specific mechanisms regulating these changes remain speculative, yet careful attention to the occurrence and time course of different types of behavioral changes can be a powerful tool for future investigations.

The issue of consistent age group definition mentioned earlier deserves critical consideration. As seen after evaluating the data presented here and in one additional cross-sectional study (57), the range of ages used in many rabbit studies (see Table 1) to form a test population representing an idealized aging population may be too broad. Several grouped rabbits up to 60 months of age with considerably younger animals. One preclinical study asserted that differences in age between treatment groups "of retired breeder rabbits [with age] minimum of 21 months old and ranged up to 44 months old" with a mean age of 28.7 months was "statistically significant, [but] is not behaviorally significant for 2- to 3-year-old rabbits"' (59). As can be seen from analyses of actual behavioral data such as that presented in the current study, such an untested assertion can be incorrect. Similarly, while anecdotal data from unpublished observations of Berry and Thompson [cited in (55, 57)] suggests that 60-month-old rabbits are more impaired than aging rabbits of less advanced age, further study is needed to fully detail age-associated impairments in the aging rabbit model. It has been suggested that in human populations, the oldest old are actually less impaired than younger cohorts, due to selective pressure 
that removes impaired individuals before they reach advanced ages.

In the present study, rabbits 12 months of age exhibited learning indistinguishable from that of younger ( 2 or 4 months old) rabbits. Rabbits 24 months of age were less impaired on all measures than older rabbits, or if evaluated with the 8 out of $10 \mathrm{CRs}$ criterion, were not significantly impaired at all. Consequently, for the hippocampally dependent Trace 500 conditioning task, an aging-impaired population can be defined as rabbits 24 months of age or older, if a rigorous behavioral criterion of $80 \%$ CRs is used. The impairment continued to increase up to 30 months of age, irregardless of the criterion used. Rabbits 36 months of age that acquired the task did so as rapidly as 30 -month-old rabbits. However, the proportion of the population that failed to acquire the task continued to increase up to (and likely beyond) 36 months of age. Rabbits 45 months of age have been reported to be more impaired than 30-month-old rabbits in acquisition of a different trace conditioning task [(57), p. 105], although the statistical significance of this effect cannot be interpreted from the published data. Further study with considerably older rabbits would seem warranted, particularly if a true senescent rabbit model equivalent to that established for other species is to be developed $(3,33,52)$. Precise definitions of age groups within a study (and restriction of these groups to ranges with demonstrable internal consistency) are vital for a clear interpretation of the experimental results.

The Trace 500 conditioned eyeblink task examined here is clearly age sensitive, and offers a stable preparation for studying the neural substrates underlying the observed behavioral deficits. The age-dependent decline in learning ability along with an increase in behavioral heterogeneity in this hippocampally dependent eyeblink conditioning task for rabbits $(21,26,44)$ is to some degree comparable with similar findings obtained using other hippocampally dependent tasks in other species, notably spatiallearning tasks performed by aging rats $(3,11,13,19,25)$. Significant individual differences between aging subjects have been reported. Given parallel age-dependent decrements in hippocampal function $(27,28)$ and in acquisition of hippocampally dependent trace conditioning occurring in aging rabbits, it can be argued that trace conditioning offers a valuable preparation for studies of agingrelated neural mechanisms. Direct comparisons of trace or delay conditioned aging subjects (17) support this conclusion. It has been hypothesized that increased CS-US intervals increase the difficulty of the eyeblink conditioning task, irrespective of whether a trace or a delay paradigm was tested (33). Our own data from young rabbits suggests that this may not be an absolute rule, as rabbits delay or trace conditioned using identical CS-US intervals exhibited widely different behavioral acquisition rates, while those delay conditioned using different CS-US intervals exhibited essentially identical rates (see Fig. 1). Additional data are required to address this issue fully in the context of aging, and are beyond the scope of the present study. Although the rabbit eyeblink preparation has been extensively developed as a model system with direct links between rabbit and human work $(4,33,41,52,55)$, the rationale for the choice of the specific experimental protocol used in different studies is not always apparent. Given the demonstrable hippocampal pathology in Alzheimer's dementia in humans (53) and the demonstrable age-associated changes in hippocampal physiology in animal models $(3,27,28)$, the hippocampally dependent trace eyeblink conditioning task may be particularly appropriate for human studies of the role of the hippocampus and other limbic structures in aging.

Eyeblink conditioning, including the Trace 500 task used in the present study, allows multiple measures (behavioral, neurochemical, electrophysiological, etc.) to be made either during training or at varying intervals thereafter, thus meeting requirements defined for efficiency in aging research $(33,37)$. A behavioral criterion of $80 \%$ CRs clearly distinguished age-associated behavioral impairments, which were significant by 24 months of age and reached asymptote by 30 months of age in the rabbit, while a criterion of 8 out of 10 CRs gave divergent results. Further, aging rabbits exhibited clear heterogeneity in their ability to acquire the trace eyeblink task when a rigorous but not when an easy behavioral criterion was used, suggesting that studies of the underlying neural substrates of age-associated learning impairments must also account for this behavioral heterogeneity.

\section{ACKNOWLEDGEMENTS}

This work was supported by NIH RO1 AG08796, DA07633, and MH47340 to J.F.D. We thank S. Conroy, F. Cutting, G. Halperin, D. Heinz, and M. McCarthy for their technical assistance in the course of this work.

\section{REFERENCES}

1. Akase, E.; Alkon, D. L.; Disterhoft, J. F. Hippocampal lesions impair memory of short-delay conditioned eyeblink in rabbits. Behav. Neurosci. 103:935-943; 1989 .

2. Akase, E.; Thompson, L. T.; Disterhoft, J. F. A system for quantitative analyses of associative learning: 2. Real-time software for MS-DOS microcomputers. J. Neurosci. Methods 54:119-130; 1994.

3. Barnes, C. A. Normal aging: Regionally specific changes in hippocampal synaptic transmission. Trends Neurosci. 17:13-18; 1994.

4. Carillo, M. C.; Thompson, L. T.; Naughton, B. J.; Gabrieli, J.; Disterhoft, J. F. Aging impairs trace conditioning in humans independent of changes in the unconditioned response. Soc. Neurosci. Abstr. 19:386; 1993.

5. Coffin, J. M.; Woodruff-Pak, D. S. Delay classical conditioning in young and older rabbits: Initial acquisition and retention at 12 and 18 months. Behav. Neurosci. 107:63-71; 1993.

6. Collier, T. J.; Coleman, P. D. Divergence of biological and chronological aging: Evidence from rodent studies. Neurobiol. Aging 12:685693; 1991.

7. Deyo, R. A.; Straube, K.; Disterhoft, J. F. Nimodipine facilitates trace conditioning of the eye-blink response in aging rabbits. Science 243 : 809-811; 1989.

8. Disterhoft, J. F.; Thompson, L. T.; Halperin, G. I.; Lanthorn, T. Dcycloserine enhances hippocampally dependent eyeblink conditioning in aging as well as young rabbits. Soc. Neurosci. Abstr. 19:1009; 1993.
9. Evans, D. A.; Funkenstein, H. H.; Albert, M. S.; Scherr, P. A.; Cook, N. R.; Chowen, M. J.; Hebert, L.; Hennekens, C.; Taylor, J. O. Prevalence of Alzheimer's disease in a community population of older persons: Higher than previously reported. JAMA 262:2551-2556; 1989.

10. Fox, R. The rabbit (Oryctolagus cuniculus) and research on aging. Exp. Aging Res. 6:235-248; 1980.

11. Gage, F. H.; Dunnett, S. B.; Björklund, A. Spatial learning and motor deficits in aged rats. Neurobiol. Aging, 5:43-48; 1984.

12. Gage, F. H.; Dunnett, S. B.; Björklund, A. Age-related impairments in spatial memory are independent of those in sensorimotor skills. Neurobiol. Aging 10:347-352; 1989.

13. Gallagher, M.; Burwell, R. D. Relationship of age-related decline across several behavioral domains. Neurobiol. Aging 10:691-708; 1989.

14. Geinisman, Y.; de Toledo-Morrell, L.; Morrell, F.; Heller, R. E. Hippocampal markers of age-related memory dysfunction: Behavioral, electrophysiological and morphological perspectives. Prog. Neurobiol. 45:223-252; 1995.

15. Geinisman, Y.; de Toledo-Morrell, L.; Morrell, F.; Persina, I. S.; Rossi, M. Structural synaptic plasticity associated with the induction of long-term potentiation is preserved in the dentate gyrus of aged rats. Hippocampus 2:445-456; 1992.

16. Gormezano, I.; Prokasy, W. F.; Thompson, R. R. Classical conditioning. Hillsdale, NJ: Erlabum; 1987. 
17. Graves, C. A.; Solomon, P. R. Age-related disruption of trace but not delay classical conditioning of the rabbit's nictitating membrane response. Behav. Neurosci. 99:88-96; 1985.

18. Harrison, J.; Buchwald, J. Eyeblink conditioning deficits in the old cat. Neurobiol. Aging 4:88-96; 1983.

19. Hyman, B. T.; Marzloff, K.; Wenniger, J. J.; Dawson, T. M.; Bredt, D. S.; Snyder, S. H. Relative sparing of nitric oxide synthase containing neurons in the hippocampal formation in Alzheimer's disease. Ann. Neurol. 32:818-820; 1992.

20. Ingram, D. K.; Lane, M. A.; Cutler, R. G.; Roth, G. S. Longitudinal study of aging in monkeys: Effects of diet restriction. Neurobiol. Aging 14:687-688; 1993.

21. Kim, J. J.; Clark, R. E.; Thompson, R. F. Hippocampectomy impairs the memory of recently, but not remotely, acquired trace eyeblink conditioned responses. Behav. Neurosci. 109:195-203; 1995.

22. Kim, J. J.; Fanselow, M. Modality-specific retrograde amnesia of fear. Science 256:675-677; 1992

23. Kowalska, M.; Disterhoft, J. F. Relationship of nimodipine dose and serum concentration to learning enhancement in aging rabbits. Exp. Neurol. 127:159-166; 1994

24. Landfield, P. W.; Pitler, T. A. Prolonged $\mathrm{Ca}^{2+}$-dependent afterhyperpolarizations in hippocampal neurons of aged rats. Science 226:10891092; 1984.

25. Markowska, A. L.; Stone, W. G.; Ingram, D. K.; Reynolds, J.; Gold, P. E.; Conti, L. H.; Pontecorvo, M. J.; Wenk, G. L.; Olton, D. S. Individual differences in aging: Behavioral and neurobiological correlates. Neurobiol. Aging 10:31-43; 1989.

26. Moyer, J. R.; Deyo, R. A.; Disterhoft, J. F. Hippocampectomy disrupts trace eye-blink conditioning in rabbits. Behav. Neurosci. 104:243$252 ; 1990$.

27. Moyer, J. R.; Disterhoft, J. F. Nimodipine decreases calcium action potentials in rabbit hippocampal CA1 neurons in an age- and concentration-dependent manner. Hippocampus 4:11-18; 1994.

28. Moyer, J. R.; Thompson, L. T.; Black, J. P.; Disterhoft, J. F. Nimodipine increases excitability of rabbit CA1 pyramidal neurons in an age-dependent and concentration-dependent manner. J. Neurophysiol. 68:2100-2109; 1992.

29. Moyer, J. R.; Thompson, L. T.; Disterhoft, J. F. Trace eyeblink conditioning increases CA 1 excitability in a transient and learning-specific manner. J. Neurosci. (submitted).

30. Penick, S.; Solomon, P. R. Hippocampus, context, and conditioning. Behav. Neurosci. 105:611-617; 1991.

31. Powell, D. A.; Buchanan, S.; Hernandez, L. L. Age related changes in classical (Pavlovian) conditioning in the New Zealand albino rabbit. Exp. Aging Res. 7:453-465; 1981.

32. Powell, D. A.; Buchanan, S.; Hernandez, L. L. Age-related changes in Pavlovian conditioning: Central nervous system correlates. Physiol. Behav. 32:602-616; 1984.

33. Powell, D. A.; Buchanan, S.; Hernandez, L. L. Classical (Pavlovian) conditioning models of age-related changes in associative learning and their neurobiological substrates. Prog. Neurobiol. 36:201-228; 1991.

34. Prokasy, W. F. A perspective on the acquisition of skeletal responses employing the Pavlovian paradigm. In: Gormezano, I.; Prokasy, W. F.; Thompson, R. F., eds. Classical conditioning. Hillsdale, NJ: Erlbaum; 1987:287-318

35. Rao, G.; Barnes, C. A.; McNaughton, B. L. Effects of age on Lglutamate-induced depolarization in three hippocampal subfields. Neurobiol. Aging 14:27-33; 1993.

36. Rapp, P. Neuropsychological analysis of learning and memory in the aged nonhuman primate. Neurobiol. Aging 14:627-629; 1993.

37. Rogers, J. Efficient experimental design in aging studies. Neurobiol. Aging 12:695-697; 1991.

38. Schmaltz, L. W.; Theios, J. Acquisition and extinction of a classically conditioned reflex in hippocampectomized rabbits (Oryctolagus cuniculus). J. Comp. Physiol. Psychol. 79:328-333; 1972.

39. Solomon, P. R. A time and place for everything? Temporal processing views of hippocampal function with special reference to attention. Physiol. Psychol. 8:254-261; 1980.

40. Solomon, P. R.; Barth, C. L.; Wood, M. S.; Velazquez, E.; GrocciaEllison, M.; Yang, B.-Y. Age-related deficits in retention of the classically conditioned eyeblink response in rabbits. Behav. Neurosci. 109: $18-23 ; 1995$.
41. Solomon, P. R.; Beal, M. F.; Pendlebury, W. W. Age-related disruption of classical conditioning: A model systems approach to memory disorders. Neurobiol. Aging 9:535-546; 1988.

42. Solomon, P. R.; Moore, J. W. Latent inhibition and stimulus generalization of the classically conditioned nictitating membrane response in rabbits (Oryctolagus cuniculus) following hippocampal ablation. J. Comp. Physiol. Psychol. 89:1192-1203; 1975.

43. Solomon, P. R.; Pomerleau, D.; Bennett, L.; James, J.; Morse, D. L. Acquisition of the classically conditioned eyeblink response in humans over the life span. Psychol. Aging 4:34-41; 1989.

44. Solomon, P. R.; Vander Schaaf, E. R.; Thompson, R. F.; Weisz, D. J. Hippocampus and trace conditioning of the rabbit's classically conditioned nictitating membrane response. Behav. Neurosci. 100:729-744; 1986.

45. Solomon, P. R.; Wood, M. S.; Groccia-Ellison, M. E.; Yang, B.-Y.; Fanelli, R. J.; Mervis, R. F. Nimodipine facilitates retention of the classically conditioned nictitating membrane response in aged rabbits over long retention intervals. Neurobiol. Aging (in press).

46. Straube, K. T.; Deyo, R. A.; Moyer, J. R.; Disterhoft, J. R. Dietary nimodipine improves associative learning in aging rabbits. Neurobiol. Aging 11:659-661; 1990.

47. Thompson, L. T.; Akase, E.; Moyer, J. R.; Disterhoft, J. F. A system for quantitative analysis of associative learning: 1 . Hardware interfaces with cross-species applications. J. Neurosci. Methods 54:109-117; 1994.

48. Thompson, L. T.; Dubocovich, M.; Disterhoft, J. F. Quantitative autoradiography of enhanced $\left[{ }^{3} \mathrm{H}\right] \mathrm{MK}-801$ binding in trace conditioned hippocampus. Soc. Neurosci. Abstr. 18:1218; 1992.

49. Thompson, L. T.; Moskal, J. R.; Disterhoft, J. F. Hippocampusdependent learning facilitated by a monoclonal antibody or Dcycloserine. Nature 359:638-641; 1992.

50. Thompson, L. T.; Moyer, J. R.; Disterhoft, J. F. Transient changes in excitability of rabbit CA3 neurons with a time-course appropriate to support memory consolidation. J. Neurophysiol. 1996 (in press).

51. Thompson, R. F. The neurobiology of learning and memory. Science 233:941-947; 1986.

52. Thompson, R. F. Classical conditioning: The Rosetta stone for brain substrates of age related deficits in learning and memory. Neurobiol. Aging 9:547-548; 1988.

53. van Hoesen, G. W.; Hyman, B. T. Hippocampal formation: Anatomy and the patterns of pathology in Alzheimer's disease. Prog. Brain Res. 83:445-457; 1990.

54. Weiss, C.; Thompson, R. F. Delayed acquisition of eyeblink conditioning in aged F1 hybrid (Fischer- $344 \times$ brown Norway) rat. Neurobiol. Aging 13:319-323; 1992.

55. Woodruff-Pak, D. S. Aging and classical conditioning: Parallel studies in rabbits and humans. Neurobiol. Aging 9:511-522; 1988.

56. Woodruff-Pak, D. S.; Coffin, J. M.; Papka, M. A substituted pyrrolidinone, BMY 21502, and classical conditioning of the nictitating membrane response in young and older rabbits. Psychobiology 22:312-319; 1994.

57. Woodruff-Pak, D. S.; Lavond, D. G.; Logan, C. G.; Thompson, R. F. Classical conditioning in 3-, 30-, and 45-month-old rabbits: Behavioral learning and hippocampal unit activity. Neurobiol. Aging 8:101-108; 1987.

58. Woodruff-Pak, D. S.; Lavond, D. G.; Thompson, R. F. Trace conditioning: Abolished by cerebellar nuclear lesions but not lateral cerebellar cortex aspirations. Brain Res. 348:249-260; 1985.

59. Woodruff-Pak, D. S.; Li, Y.-T. Nifiracetam (DM-9384): Effect on eyeblink classical conditioning in older rabbits. Psychopharmacology (Berlin) 114:200-208; 1994.

60. Woodruff-Pak, D. S.; Li, Y.-T.; Kem, W. R. A nicotinic agonist (GTS21 ), eyeblink classical conditioning, and nicotinic receptor binding in rabbit brain. Brain Res. 645:309-317; 1994.

61. Woodruff-Pak, D. S.; Steinmetz, J. E.; Thompson, R. F. Classical conditioning of rabbits $2-1 / 2$ to 4 years old using mossy fiber stimulation as a CS. Neurobiol. Aging 9:187-193; 1988.

62. Zola-Morgan, S. M.; Squire, L. R. The primate hippocampal formation: Evidence for a time-limited role in memory storage. Science 250:288-290; 1990. 